\title{
Diel transcriptional response of a California Current plankton microbiome to light, low iron, and enduring viral infection
}

\author{
B. C. Kolody ${ }^{1,2}$ - J. P. McCrow ${ }^{2} \cdot$ L. Zeigler Allen ${ }^{1,2} \cdot$ F. O. Aylward ${ }^{3} \cdot$ K. M. Fontanez ${ }^{4}$ A. Moustafa ${ }^{5}$.

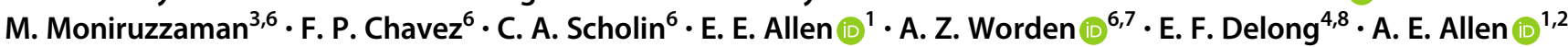

Received: 9 November 2018 / Revised: 11 June 2019 / Accepted: 15 June 2019 / Published online: 18 July 2019

(c) The Author(s) 2019. This article is published with open access

\begin{abstract}
Phytoplankton and associated microbial communities provide organic carbon to oceanic food webs and drive ecosystem dynamics. However, capturing those dynamics is challenging. Here, an in situ, semi-Lagrangian, robotic sampler profiled pelagic microbes at $4 \mathrm{~h}$ intervals over $\sim 2.6$ days in North Pacific high-nutrient, low-chlorophyll waters. We report on the community structure and transcriptional dynamics of microbes in an operationally large size class $(>5 \mu \mathrm{m})$ predominantly populated by dinoflagellates, ciliates, haptophytes, pelagophytes, diatoms, cyanobacteria (chiefly Synechococcus), prasinophytes (chiefly Ostreococcus), fungi, archaea, and proteobacteria. Apart from fungi and archaea, all groups exhibited 24-h periodicity in some transcripts, but larger portions of the transcriptome oscillated in phototrophs. Periodic photosynthesis-related transcripts exhibited a temporal cascade across the morning hours, conserved across diverse phototrophic lineages. Pronounced silica:nitrate drawdown, a high flavodoxin to ferredoxin transcript ratio, and elevated expression of other Fe-stress markers indicated Fe-limitation. Fe-stress markers peaked during a photoperiodically adaptive time window that could modulate phytoplankton response to seasonal Fe-limitation. Remarkably, we observed viruses that infect the majority of abundant taxa, often with total transcriptional activity synchronized with putative hosts. Taken together, these data reveal a microbial plankton community that is shaped by recycled production and tightly controlled by Fe-limitation and viral activity.
\end{abstract}

\section{Introduction}

Phytoplankton productivity is essential for supporting marine food webs and represents a key variable in

Supplementary information The online version of this article (https:// doi.org/10.1038/s41396-019-0472-2) contains supplementary material, which is available to authorized users.

$\triangle$ A. E. Allen

aallen@jcvi.org

1 Scripps Institution of Oceanography, University of California, San Diego, CA 92093, USA

2 Microbial and Environmental Genomics Group, J. Craig Venter Institute, La Jolla, CA 92037, USA

3 Department of Biological Sciences, Virginia Tech, Blacksburg, VA 24061, USA

4 Department of Civil and Environmental Engineering, Massachusetts Institute of Technology, Cambridge, MA 02139, USA biogeochemical cycling and climate models [1]. Primary productivity is often determined locally by eddy-scale upwelling and molecular-scale interactions between bacteria, viruses, grazers, and phytoplankton [2, 3]. As a result of observational limitations of these molecular-scale processes in situ, much of our knowledge of phytoplankton physiology derives from laboratory-based experiments. Such studies have been instrumental in elucidating the basic biology and genetic potential of many individual

5 Department of Biology and Biotechnology Graduate Program, American University in Cairo, New Cairo, Egypt

6 Monterey Bay Aquarium Research Institute, Moss Landing, CA 95039, USA

7 Ocean EcoSystems Biology Unit, GEOMAR Helmholtz Centre for Ocean Research, Kiel, DE, Germany

8 Daniel K. Inouye Center for Microbial Oceanography: Research and Education (C-MORE), University of Hawaii, Honolulu, HI 96822, USA 
phytoplankton [4-8], however, they cannot capture ecological interactions with uncultured community members or the influence of the advection dynamics found in nature.

Recently, the Environmental Sample Processor (ESP) [9], a robotic sampling device, has been deployed in a drifter configuration to follow sympatric populations of small $(<5 \mu \mathrm{m})$ microbes within a particular water mass. These studies elucidated diel transcriptional rhythms first in the picophytoplankton, Synechococcus and Ostreococcus [10], and later in heterotrophic bacterioplankton [11] and viruses [12]. A comparison of drifts from diverse environments revealed a daily "cascade" of transcriptional activity across taxa that was conserved on ocean basin scales [13].

However, it is unknown whether these findings extend to the majority of eukaryotic primary producers (diatoms, haptophytes, pelagophytes, chlorophytes, etc.), planktonic predators such as ciliates and dinoflagellates, and particleassociated microbes. If diel transcriptional rhythms exist in these taxa, do similar functions co-occur across diverse lineages, or do they fall in a temporal cascade? In addition, it is unknown to what extent abiotic factors such as nutrient limitation affect the prevalence of diel transcription.

Here, we analyzed the large size-class filters associated with the initial deployment of the ESP [10], which collected whole-community RNA samples every $4 \mathrm{~h}$ over $\sim 2.6$ days in the central California Current upwelling system (cCCS). Because of the semi-Lagrangian nature of this ESP deployment (Fig. S1a), a coherent microbial community was observed in both size classes, providing a unique record of its diel response to changes in sunlight as well as in situ nutrient conditions and prevailing ecosystem dynamics. We asked whether the timing and function of diel transcription was conserved across diverse, uncultured protist lineages, as well as how productivity was affected by local iron stress. In addition, access to both filters allowed us to juxtapose free-living microbes with those putatively associated with particles in the same environment, and compare the role of viruses in both fractions.

\section{Materials and methods}

Full methods, including methods for rRNA amplicon processing and phylogenetics, are described in Supplementary File 1, and raw data can be accessed at NCBI (BioProject accession number PRJNA492502; BioSample accession numbers SAMN10104964-SAMN10105011). Processed data can be found in Supplementary Datasets 1-12, and are described in Supplementary File 3. Briefly, $1 \mathrm{~L}$ samples were collected every $\sim 4 \mathrm{~h}$ (16 samples in total) by an ESP suspended $23 \mathrm{~m}$ below a semi-Lagrangian surface float as previously described [10] from September 16-19, 2010. Seawater was size fractionated in situ onto large fraction
$(5 \mu \mathrm{m})$ and small fraction $(0.22 \mu \mathrm{m})$ filters. cDNA for metatranscriptomes was prepared as described in Ottesen et al. [10] from ribosomal RNA-depleted total RNA [10].

Metatranscriptome quality control, trimming, filtration, and rRNA removal was conducted on large fraction Illumina reads and the previously reported small fraction 454 reads via the RNAseq Annotation Pipeline v0.4 (Fig. S2) [14]. Ab initio open-reading frames (ORFs) were predicted on assembled large fraction contigs and unassembled small fraction 454 reads. ORFs were annotated via BLASTP [15] alignment to a comprehensive protein database, phyloDB (Supplementary File 1). To avoid biases introduced by classifying ORFs based on best BLAST to potentially contaminated sequences, particularly important when using microbial reference transcriptomes obtained from nonaxenic laboratory cultures, a Lineage Probability Index (LPI) was used to assign taxonomy [14, 16, 17]. LPI was calculated here as a value between 0 and 1 indicating lineage commonality among the top 95-percentile of sequences based on BLAST bit-score [14, 16]. For each taxa group, the references with the highest mean percent identity to ab initio ORFs and that recruited the most ORFs were used for nucleotide-space mapping. References with at least 1000 genes with at least five reads mapped were then considered for downstream analysis. Coverage statistics are provided in Fig. S3. Reference ORFs were hierarchically clustered together with ab initio ORFs from both fractions to form peptide ortholog groups and assigned a consensus annotation. ORFs with significantly periodic diel expression were identified using harmonic regression analysis (HRA) as previously described $[10,11,13]$. The Weighted Gene Correlation Network Analysis (WGCNA) R package [18] was used as previously described [13] to identify modules of conserved expression among ORFs and functional clusters.

\section{Results and discussion}

The ESP was deployed offshore of Big Sur in the cCCS "transition zone" between nutrient-dense coastally-upwelled water and the oligotrophic open ocean. Despite sustaining highly productive fisheries, this region is characterized by frequent, variable levels of iron stress $(\mathrm{Fe}<0.2 \mathrm{nmol} / \mathrm{kg}$; Fig. S4) and concordant high residual nitrate $(5-15 \mu \mathrm{M})$ and low chlorophyll $(1-2 \mu \mathrm{g} / \mathrm{l}$; refs. [19-22]). We measured high nitrate $(5-13 \mu \mathrm{M})$ and low-chlorophyll concentrations $(<1 \mu \mathrm{M}$; Fig. S1b) in addition to a silica:nitrate ratio indicative of iron stress. Silica:nitrate ratios in the range of 0.8-1.1 are associated with iron limitation [20] and are thought to result from silica drawdown by iron-stressed diatoms [23]. In our study, this ratio was initially around 1 and dropped by an order of magnitude along the drift track 
(Fig. S1b). Molecular evidence, including expression of several low-iron response genes and a strikingly high flavodoxin:ferredoxin ratio, also supported iron limitation (Supplementary File 1, Fig. S5).

\section{Taxonomic structure of the active community}

The mRNA taxonomic assignments depicted an active community that was stable over time for both size fractions. This was the case at both coarse taxonomic (Fig. 1a) and genus (Fig. S6) levels, indicating that the drift track sampled a sympatric community of plankton. Large fraction mRNA activity was dominated by photosynthetic eukaryotes for which mapping to reference transcriptomes generally averaged $<80 \%$ nucleotide identity (Figs. S7 and S8). In all, $45.9 \%$ of ab initio ORFs did not have any database match, a testament to the breadth of novel plankton diversity that remains uncultured, even in coastal regimes.

Dinoflagellates were the largest identifiable contributor to large size-class activity $34.8 \%$ of library normalized reads; Fig. 1a), with Alexandrium, Karenia, and Karlodinium each accounting for $\sim 20 \%$ of dinoflagellate mRNA (Fig. S6e). Phylogenetic analysis of 18S rRNA amplicons (Fig. S9) also depicted a community dominated by dinoflagellates, and 16S rRNA amplicons from chloroplasts (Fig. 1b) confirmed that many were photosynthetic. While copy number variation is a potential source of bias for $18 \mathrm{~S}$ amplicon data [24], here our $18 \mathrm{~S}$ community structure is largely in agreement with our transcript-based annotations. Non-plastid 16S rRNA amplicons from the large size class were dominated by cyanobacteria, Bacteriodetes, and Proteobacteria (Fig. S10).

Other major large fraction taxa included centric diatoms (10.3\% of mRNA), ciliates $(9.0 \%)$, metazoans $(6.2 \%)$, haptophytes $(5.2 \%)$, green algae $(5.0 \%$, primarily prasinophytes), Synechococcus (4.6\%), and pelagophytes (4.5\%). Diatoms and pelagophytes were overwhelmingly dominated by Chaetoceros (Fig. S6d) and Pelagomonas (Fig. S6g), respectively, while Ostreococcus and Phaeocystis dominated green algae and haptophytes to a lesser extent (Fig. S6a, f). Several of these taxa were previously shown to have high cell abundances in non-fractionated samples using quantitative methods during this drift and in other regional studies [25-28].

In order to address the entire community, we also used the size-fractionated data to distinguish putatively particleassociated (large fraction) from free-living (small fraction) taxa [29-31]. Fungi were significantly enriched in the large fraction (EdgeR FDR <0.05; $\log _{2} \mathrm{FC}=-5.2$ ) and highly expressed a cellulose degrading glycoside hydrolase family 7 enzyme (Fig. 1a, Supplementary Data 6). Recently, fungi were shown to be among the most important eukaryotes on bathypelagic marine snow [32]. Hence, our results illustrate that their importance in particle ecology likely extends into the surface ocean. Likewise, many prokaryotes significantly enriched in the large fraction (EdgeR FDR <0.05) have been commonly associated with particles, such as the Cytophaga (2.3\% of bacterial expression) and Planctomyces $(0.5 \%)$ (Supplementary Dataset 10$)$. These taxa are important recyclers of structural and storage forms of carbon [33, 34], and we found active expression of bacterial organic matter degrading enzymes, such as glycoside hydrolase family 16 and secreted glycosyl hydrolases (Supplementary Dataset 6). Furthermore, the comEA and comEC gene clusters for the bacterial process of taking up exogenous DNA (competence) were enriched in the large fraction (EdgeR FDR <0.05; Supplementary Dataset 8) and expressed across 11 large fraction bacterial genera. Particleattached bacteria may have taken up exogenous DNA, potentially as a nutrient source, for DNA repair, or to increase genetic diversity [35], as seen in Vibrios attached to chitin [36].

\section{Patterns of community activity}

In the large size class, total gene expression was often highly synchronized between members of a given taxonomic group (Fig. S11a), especially among prokaryotes. For example, flavobacteria and euryarchaeota ORFs showed strong ingroup correlation (Fig. S11a; Pearson's $r=0.94$, 0.93, respectively) and were most highly expressed at night (Fig. S11c, d). In total, HRA detected ten large-fraction taxa, including the diatom, Skeletonema sp., and the bacteria, Roseobacter sp., with total gene expression that followed smooth day/night oscillation with a period of $24 \mathrm{~h}$ (Fig. S12).

\section{Functional characterization of the active community}

WGCNA on functional clusters established six unique patterns ("modules") of gene expression over time in the large fraction and three in the small fraction (Fig. 2). WGCNA on nucleotide sequences aligned to reference transcriptomes recapitulated major functions but did not capture the same breadth of novel phylogenetic diversity that resulted from aligning amino acid sequences of $a b$ initio ORFs (Fig. S13). Ab initio analysis established 344,615 unique ORFs which recruited $\sim 107$ million reads, whereas mapping reads to reference transcriptomes captured only $\sim 15$ million reads mapping to 168,349 reference ORFs.

In the large size class, the most obvious drivers of gene expression were taxonomy and day/night cycles. The most abundant cluster in large fraction module 1 (Fig. 2; turquoise; up at night) was a small subunit ribosomal protein, almost entirely composed of centric diatoms. Interestingly, prokaryotic and eukaryotic viral capsids both clustered into 


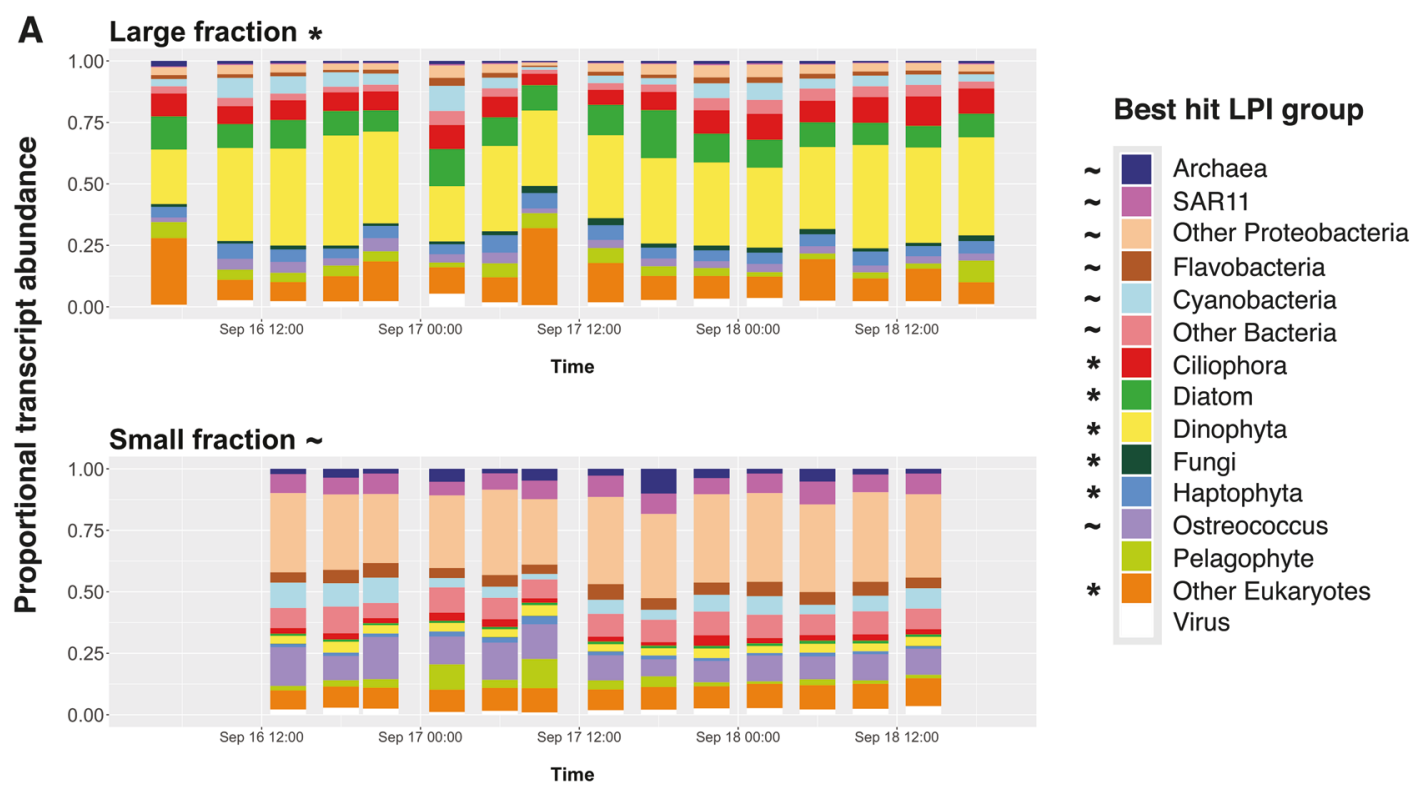

B

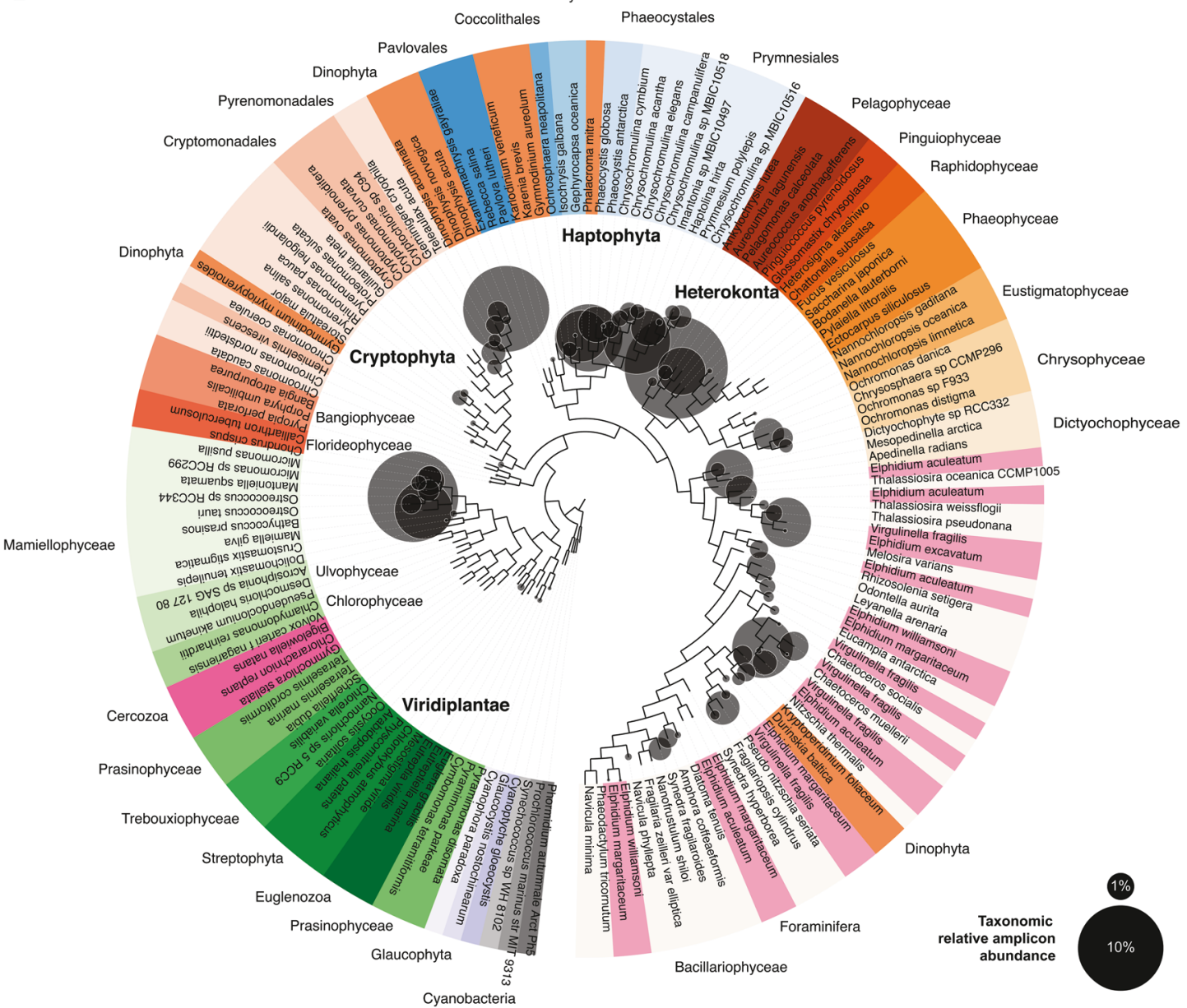


Fig. 1 Major taxa found in the eastern North Pacific drift track. a Taxonomically annotated total community expression over time across size classes. Expression includes only non-organellar ORFs and is normalized by library (time point) within each fraction. Taxa grouping of each ab initio ORF is determined by best LPI hit. Asterisks and tildes denote taxa groups significantly enriched in the large and small size classes, respectively (edgeR, FDR <0.05). b Phylogenetic reconstruction of $16 \mathrm{~S}$ rRNA gene reference sequences and distributions of active plastids represented in terms of cDNA-based amplicon relative abundances summed across all time points (circles; Supplementary Dataset 5). Circles representing relative amplicon abundance are superimposed over a reference phylogeny which is colored by taxonomy. Proximity of circles to the tips of the branches represents closeness of observed sequences to the references and circle sizes are proportional to normalized read abundance. Note that dinoflagellates known to have tertiary plastids are placed in this method according to the plastid origins (e.g., Gymnodinium myriopyrenoides and several Dinophysis species clading with cryptophytes [93])

this night-up module. Large fraction module 2 (blue; erratic) echoed the shape of overall dinoflagellate activity (Fig. S11a), and major cluster annotations (e.g., tubulin, bacteriorhodopsin-like protein, and bacterial DNA-binding protein (the dinoflagellate equivalent of histones [37])) were dominated by dinoflagellates. Module 5 (green; peaks in the early morning), on the other hand, was dominated by photosynthesis-related annotations such as chlorophyll A-B binding protein and G3P dehydrogenase but also contained metazoan histones.

In the small fraction, the majority of cluster annotations were in module 1 (Fig. 2; orange; up during first night). Most functions related to growth (ribosomal proteins, RNA polymerase, and elongation factor $\mathrm{Tu}$ ) and nutrient acquisition (branched-chain amino acid transporters, Nit Tau family transport system, and multiple sugar transport system) and were dominated by Proteobacteria. Photosynthesis-related transcription in the small fraction could mostly be attributed to Ostreococcus, "other eukaryotes", and Synechococcus.

\section{Physiological response of phytoplankton to day/night cycles}

In addition to identifying data-driven patterns of gene expression with WGCNA, we also sought to probe diel physiology by fitting gene expression to a sinusoid with a $24 \mathrm{~h}$ period (HRA). Large portions of photoautotroph transcriptomes have been observed to oscillate with a 24-h period, often by known circadian mechanisms (e.g., Arabidopsis thaliana [38], Synechococcus elongatus [39], and Ostreococcus tauri [40]). Most previous observations of this light response were performed in artificially stable laboratory settings (e.g., 12:12-h light:dark cycles), but Ottesen et al. [10] observed a high number of Synechococcus and Ostreococcus transcripts in the small size fraction of this drift, including key clock, respiration, and photoautotrophy genes, oscillating with a 24-h period in natural environments [10].

Here, we expand this analysis to natural populations of large microbial eukaryotes for the first time. We observe significant diel transcriptional periodicity $(F D R \leq 0.1)$ in all active phytoplankton lineages, as well as in ciliates and some bacteria, and Synechococcus and Ostreococcus ORFs present in the large fraction (Fig. 3).

In addition, we detected phylogenetically novel Light-Oxygen-Voltage (LOV) domains, which have been implicated in transcriptional light response, including as a zeitgeber for the circadian clock [41]. LOV proteins in our data were associated with a range of effector domains, including kinases and b-ZIP transcription factors. LOV domains have rarely been characterized in marine plankton [42] and here demonstrated clear activity peaking just before dawn (Fig. S14).

\section{Timing of diel expression differed across taxonomic groups}

Significantly periodic ORFs were classified into four bins based on the time of day of peak expression (Fig. 3). Most photosynthetic eukaryotes had periodic expression in all four bins, but the majority of expression from diel ORFs occurred in the day (Fig. 3c). Ciliates and other largely heterotrophic eukaryotes, on the other hand, had eveningdominated periodic expression [43]. For prokaryotes, the results were more mixed (Supplementary File 1).

\section{Timing of diel expression was partitioned by function}

Across taxa groups, periodic non-organellar ORFs most commonly peaked in early day ( 11 a.m.) and early night ( 11 p.m.; Fig. 3d). Morning-peaking ORFs, coincident with peak photosynthetically active radiation, were dominated by photosynthesis and carbohydrate and lipid metabolism annotations. Evening-peaking ORFs related to chromatin structure and dynamics, cytoskeleton, and chromosome partitioning, possibly because evening-timed cell division minimizes UV-stress to an exposed genome [44, 45]. Comparative transcriptomics on Ostreococcus, Chlamydomonas, and Arabidopsis grown under alternating light:dark periods corroborates this conserved temporal partitioning of photosynthesis and cell-cycle genes [46].

WGCNA on all periodic ORFs independently recreated expression modules peaking in the early day, late day, early night, and late night (Fig. 3b). The early day module was most abundant, and was dominated by photosynthetic reaction center and chlorophyll $\mathrm{AB}$ binding proteins largely expressed by haptophytes, centric diatoms, pelagophytes, and some Synechococcus and Ostreococcus (Fig. 3e; red). 


\section{Large fraction ( $>5 \mu \mathrm{m})$ functional clusters}

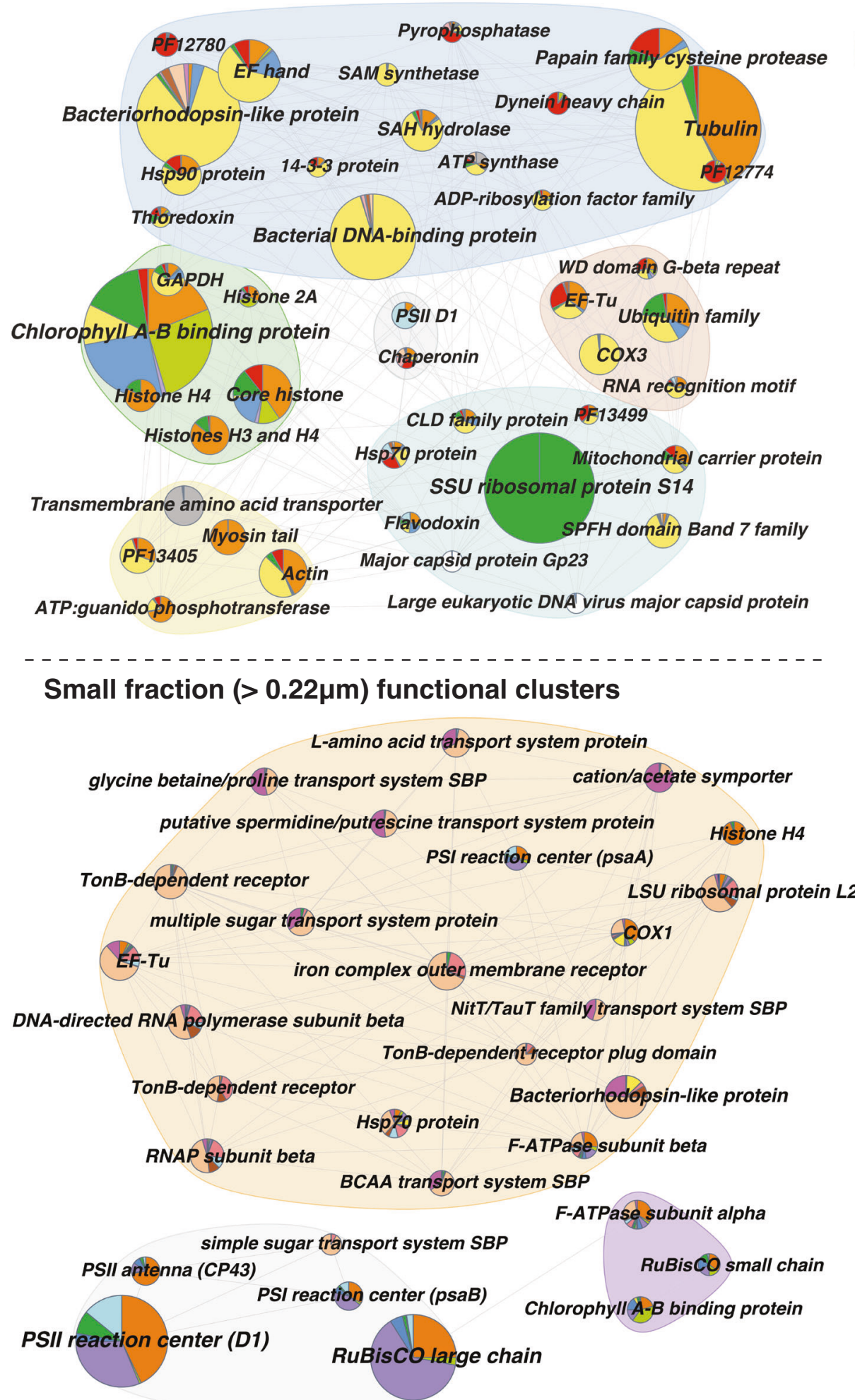

Cluster expression scale (Percent of total reads in size class)

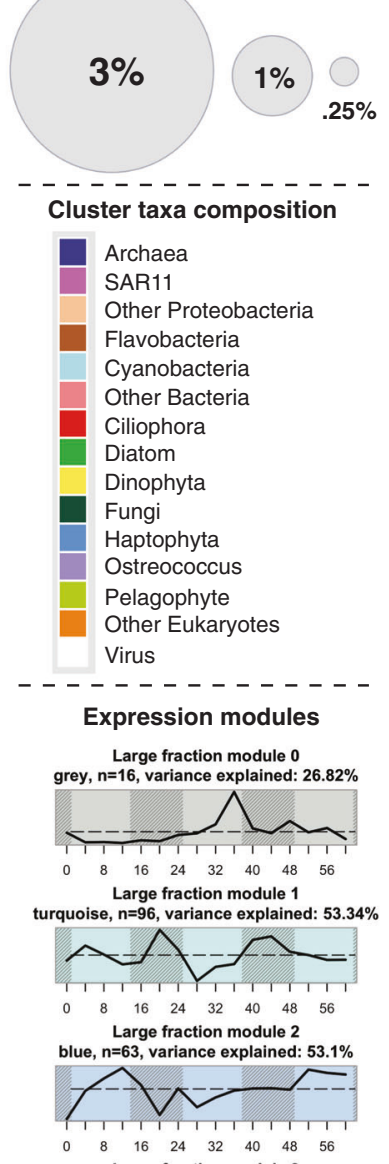
Large fraction module 3 2, variance explained: $58.34 \%$

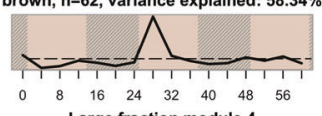
Large fraction module 4
yellow, $n=39$, variance explained: $49.47 \%$ green, $\mathbf{n = 3 2 , \text { variance explained: } 5 7 . 3 3 \%}$ $\begin{array}{llllllll}0 & 8 & 16 & 24 & 32 & 40 & 48 & 56\end{array}$ Small fraction module 0 grey, $n=37$, variance explained: $36.11 \%$

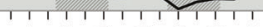
$\begin{array}{lllllll}8 & 16 & 24 & 32 & 40 & 48 & 56\end{array}$ Small fraction module 1 range, $n=683$, variance explained: $58.36 \%$ orange, $n=683$, variance explained: $58.36 \%$ 1111 1111111

$\begin{array}{lllllll}8 & 16 & 24 & 32 & 40 & 48 & 56\end{array}$ avender, $n=30$, variance explained: $69.77 \%$

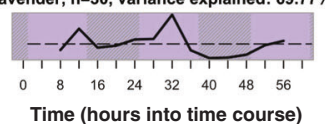

Fig. 2 A comparison of functional diversity across the large and small size classes. Pies represent highly abundant $(>0.25 \%$ total size-class expression) annotated functional clusters of $a b$ initio ORFs. Pies are colored by relative taxonomic contribution and grouped by modules of similar expression as given by WGCNA 
Fig. 3 Timing, abundance, and diversity of significantly diel large fraction ab initio ORFs (HRA on taxa group normalized ORFs; FDR $\leq 0.1)$. ORFs are categorized into four, 6-h long bins based on peak expression time: early day (red, 6 a. m.-12 p.m.), late day (yellow, 12 p.m. -6 p.m.), early night (green, 6 p.m.-12 a.m.), and late night (purple, 12 a.m.-6 a.m.). a Percent of total expression found to be significantly periodic across taxa groups. b Data-driven WGCNA modules of significantly periodic large fraction ORFs independently recreate peak expression time bins. Subtitles show percent of variance that can explained by each module's average expression profile. c Periodic expression colored by time of day bin across taxa groups. d Peak expression time of nuclear ORFs belonging to major phytoplankton players. Significantly periodic ORFs are depicted by colored dots, where colors correspond to KOG class; all other ORFs depicted in gray. The majority of periodic ORFs peak in early day (red; $54.8 \%$ ) and early night (green; $31.2 \%$ ). e Top annotated cluster annotations of significantly periodic large fraction ORFs. Pies are colored by relative taxonomic contribution (legend, right) and grouped by modules of similar expression (b)
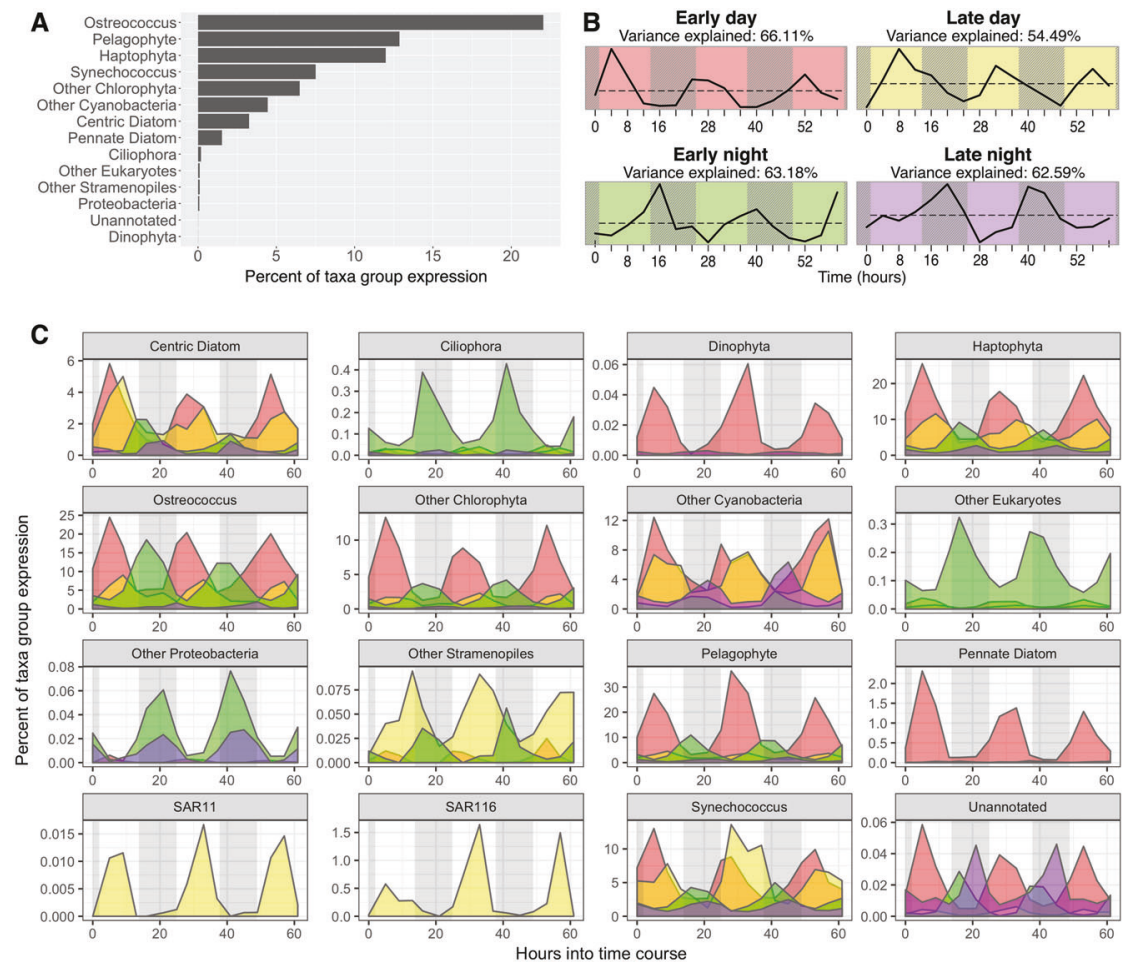

D

$$
\begin{array}{r}
\text { Cyanobacteria } \\
\text { Ciliophora } \\
\text { Diatom } \\
\text { Dinophyta } \\
\text { Haptophyta } \\
\text { Ostreococcus } \\
\text { Pelagophyte } \\
\text { Other Eukaryotes } \\
\text { Time of day }
\end{array}
$$
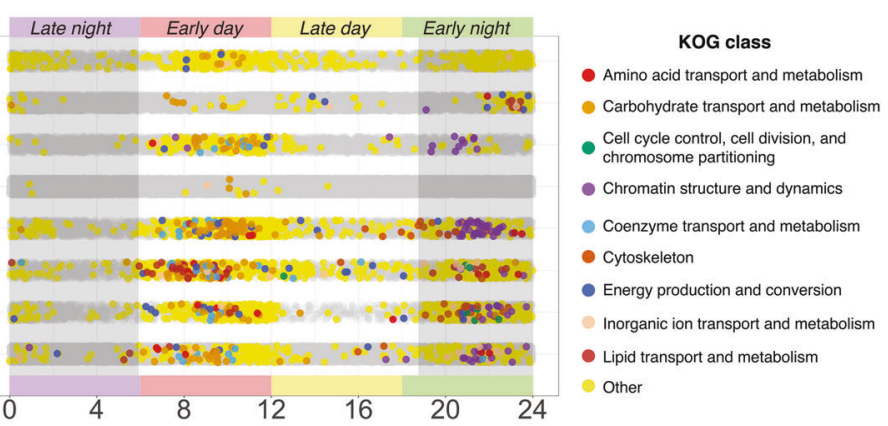

E

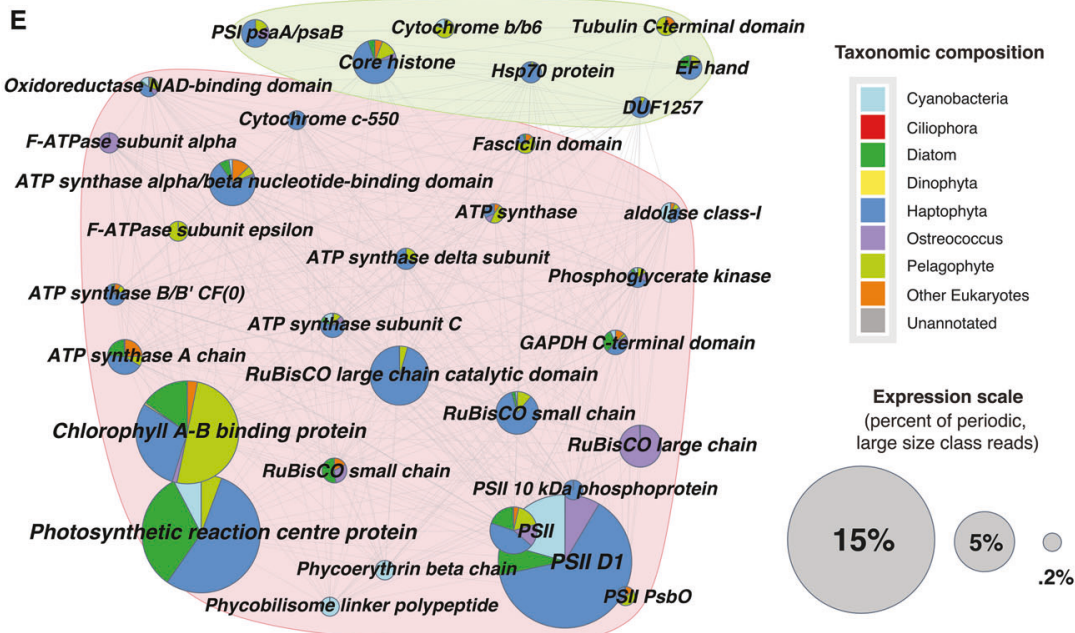

This is consistent with laboratory findings for Ostreococcus [47] and vascular plants [38, 48] where mean peak expression of light harvesting and photosynthesis genes occurs in the middle of the day. Because our data is compositional in nature, it is a useful positive control to corroborate these established results with both WGCNA 
and HRA. When sampled in constant light (after a brief entrainment to 12:12-h light:dark cycles), many Arabidopsis nuclear-encoded photosynthesis genes also peak at "midday" [38], suggesting that the conserved midday peak we observe is circadian in nature. The high-turnover nature of the photosynthetic reaction center protein pool [49] makes it likely that the $11 \mathrm{a} . \mathrm{m}$. peak expression of these transcripts correctly captures the timing of protein activity. The morning peak also contained a large number of transcripts for rubisco and ATP synthase, suggesting that carbon fixation and energy production are similarly timed. Chlorophyll synthesis ORFs (e.g., CobN/magnesium chelatase and geranyl reductase) also peaked at 11 a.m. across taxa groups, except in Proteobacteria, where bacteriochlorophyll synthesis peaked around midnight (Fig. S15c). Metabolism-related ORFs, including various ATP synthases, mitochondrial carrier proteins, phosphogylceride kinase, fructose-biphosphate aldolase, and fatty acid desaturase shared this mid-morning peak, but a second set of ATP synthases and mitochondrial carrier protein ORFs peaked in the early night coincident with cytochrome $\mathrm{C}$ oxidase and NADH-ubiquinone/plastoquinone oxidoreductase (Fig. S16a).

The early night module (Fig. 3e; green) contained an abundance of histones, especially from haptophytes and pelagophytes. DNA polymerases, condensins, cyclins, and CDKs also peaked around 11 p.m. across several photosynthetic eukaryotes (Fig. S15b). Synchronized populations of Synechococcus [50], Ostreococcus [47], Chlamydomonas [51], Phaeodactylum [6], Emiliania [52], and Pelagomonas [53] divide in early night when grown on a 12:12-h light:dark cycle, consistent with the cell division machinery we observed peaking at night in Synechococcus, Ostrococcus, prasinophytes, diatoms, haptophytes, pelagophytes, and other eukaryotes. Axonemal ORFs were significantly periodic across a broad range of motile taxa, including pelagophytes (14 ORFs), ciliates (2 ORFs), haptophytes (1 ORF), and chlorophytes (1 ORF), all peaking in the early evening (mean $\sim 9$ p.m.).

Translation-related ORFs were also periodic across many lineages. Translation initiation factors were periodically transcribed in centric diatoms, ciliates, haptophytes, other chlorophytes, pelagophytes, and Synechococcus (Fig. S16d). Interestingly, we identified several periodic eukaryotic translation elongation factor 3 (eEF3) ab initio ORFs in the large fraction (Fig. S16d). Previously believed to be unique to fungi, eEF3 presents a novel peptide synthesis mechanism for phytoplankton.

\section{Physiological interpretation of diel transcriptional partitioning}

For high-turnover proteins, diel transcription is likely important for maintaining appropriate protein levels.
However, many protein pools turnover too slowly for diel transcription to translate into diel changes in protein abundance, which is determined not only by transcription rates, but also translation and degradation rates. In Arabidopsis, Ostreococcus, and Cyanothece, the majority of proteins have half-lives that span multiple diel cycles [54]. In S. elongatus, only about $5 \%$ of proteins exhibit the diel dynamics that $30-60 \%$ of transcripts do [54, 55]. In O. tauri, under $10 \%$ of proteins are rhythmic despite nearly the whole transcriptome oscillating [56]. In this lowturnover case, diel transcriptional rhythms are more difficult to interpret.

One explanation for diel cycling transcripts in the case of stable protein abundance is "translational coincidence", a mechanism described in Arabidopsis in which the timing of transcription and translation interact to optimize use of solar energy for a given photoperiod [54]. In photosynthetic organisms spanning cyanobacteria, chlorophyte, and plant lineages, protein synthesis rates are 3-5 times higher during day than night [54]. In a dawn-tracking circadian clock, transcripts that peak in the late day during a long photoperiod (e.g., summer) peak after sunset during a short photoperiod (e.g., winter; Fig. 4a). Proteins with late-day transcripts would therefore be more abundant in long photoperiods because of reduced translation rates after sunset. In contrast, transcripts peaking in the early day or late night would not have seasonally variable protein pools. This mechanism is not only highly relevant for plants, in which seasonal adaptations spanning diverse physiological mechanisms from flowering to freezing tolerance are well described [54], but are also likely critical for unicellular algae. Seasonal phenotypes are poorly described in algae due to difficulty of observation, but some examples have been reported. For example, in response to short photoperiods (e.g., winter) Lingulodinium forms cysts and Chlamydomonas suppresses zygospore germination [57].

To assess what functions might be influenced by such seasonal adaptation, we analyzed 276 significantly periodic nuclear ORFs that peaked within the window in which seasonal adaptation would be expected (9.9-14.4 h after local dawn; Fig. 4b). All taxa groups that showed significantly periodic activity had ORFs peaking in this window except dinophyta and "other Proteobacteria". In the cCCS transition zone, iron limitation increases in tandem with photoperiod as the upwelling season progresses from spring into late summer [21]. Because iron is a photosynthetic cofactor, the stress of increased day length and low-iron likely compound in this season.

Indeed, the top annotations peaking in the seasonally adaptive window are implicated in responding to low iron and UV-stress. The most highly expressed annotation was the calcium-binding domain, EF-hand. Calcium signaling is best known in algae as being required for photoacclimation 

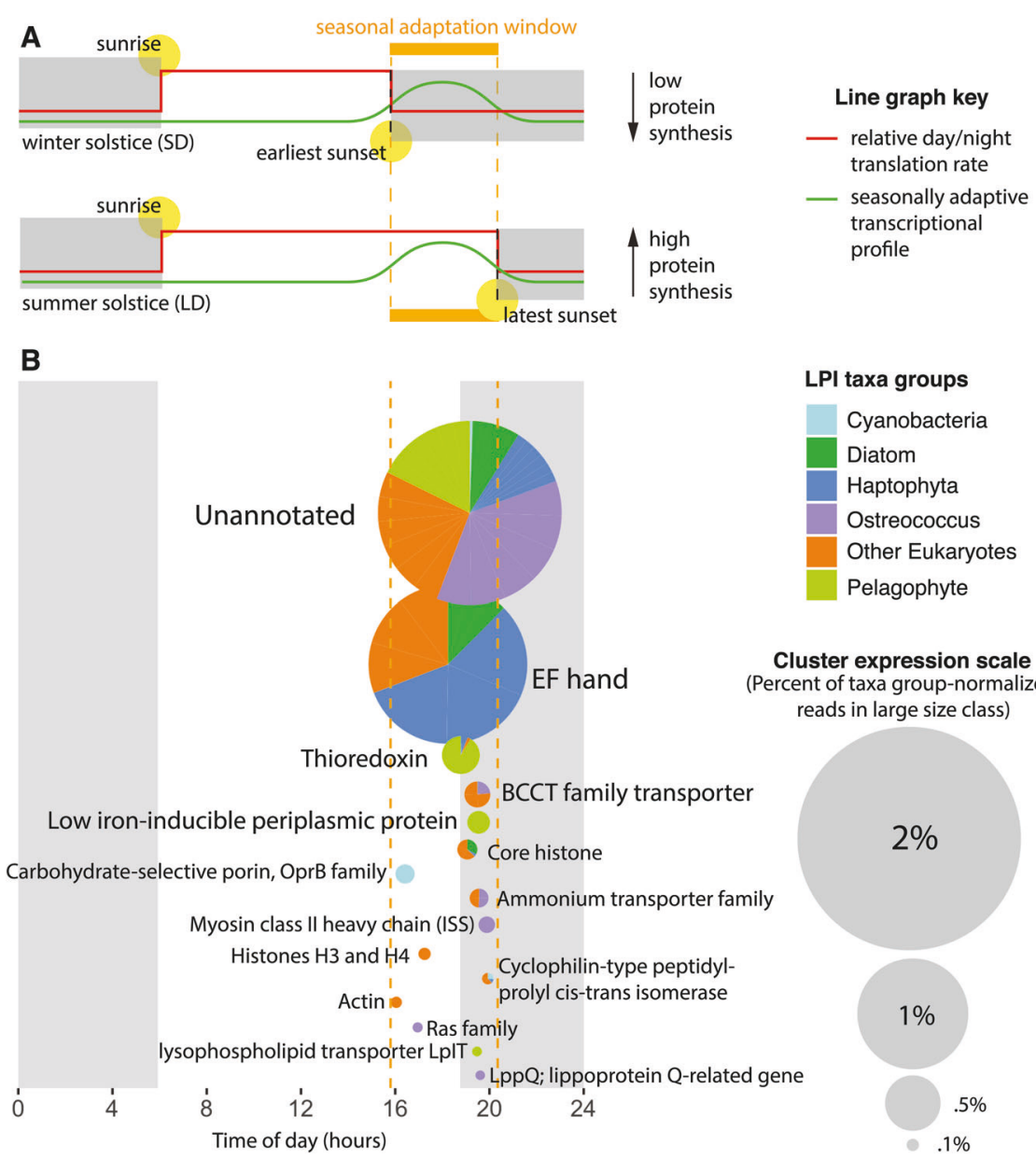

Cluster expression scale Crcent of taxa group-normalized reads in large size class)

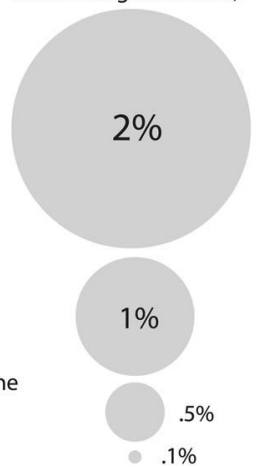

Fig. 4 Translational coincidence as a mechanism for seasonal adaptation in algae. a Schematic adapted from Seaton et al. [54] depicting the translational coincidence mechanism. The top graphic represents the shortest photoperiod of the year, the winter solstice (December 21, 2010); the bottom graphic represents the longest photoperiod of the year, the summer solstice (June 21, 2010). An ORF (green line) peaking in the early night during short day (SD) conditions (top) would peak in the late day during long day (LD) conditions (bottom).

[58] and low-iron response [59]. EF-hand-containing proteins, specifically, are associated with the low-iron phenotype in diatoms and haptophytes [8, 60]. The second most abundant annotation, thioredoxin, modulates the activity of photosynthesis proteins in response to light by sensing redox potential [61]. Three thioredoxins were significantly upregulated during long photoperiods in the Arabidopsis proteome [54]. Finally, low-iron-inducible periplasmic protein was the fourth most abundant annotation, and was dominated by the iron-uptake protein ISIP2A (phytotransferrin; ref. [62]).

When viewed with WGCNA, ISIP2A expression clustered with silicon transporters (Fig. S5, module 5; Supplementary File 1). Both were chiefly expressed by centric diatoms, which may be more sensitive to iron stress [63]
Because the average translation rate (red line) is much higher during daylight hours than night hours (gray boxes), an ORF peaking in this "seasonal adaptation window" (orange) would be upregulated in LD at the protein level. b Top non-organellar cluster annotations from the large size class of our drift track that are significantly diel and peak in the seasonal adaptation window (orange dashed lines). Pies are colored by relative taxonomic contribution and scaled to reflect proportional transcript abundance (legends, right)

because they tend not to use the ferritin mechanism favored by bloom-forming pennates. The expression pattern of module 5 had some day/night signal, but also peaked strikingly at the end of the drift track, when the silica:nitrate ratio dropped most dramatically. Low silica:nitrate ratios have been observed in association with iron limitation [20] and are thought to result from silica drawdown by ironstressed diatoms [23]. This convolution of the influence of day/night cycles and nutrient limitation on patterns of expression is indicative of how transcription may be responding to multiple drivers in a dynamic natural context. Whereas the "up-at-dusk" component of module 5 expression could be a circadian-driven mechanism allowing the phytoplankton to be generally more responsive to iron stress in the season when it is most exacerbated, the apparent 
additional level of upregulation on day three is likely a response to local conditions-namely, increasing iron stress at the end of the drift.

\section{Cascade of photosynthetic activity takes place in the morning}

In contrast to the long-lived proteins whose diel transcription may be seasonally relevant, short-lived proteins with diel oscillating mRNA are likely of daily importance. In our data, periodic photosynthesis ORFs peaked at a mean of 10:53 a.m. based on a sinusoidal fit (dashed line; Fig. 5a), but components of the photosynthetic apparatus peaked in a "cascade" throughout the morning, beginning around 9 a.m. with the phycobilisome (orange) and cytochrome b6f complex (lavender), and ending around noon with PSII reaction center D1/D2 (blue). fts $H$ protease was also periodic and peaked in time with photosynthesis genes in cyanobacteria and in eukaryotes. This is likely due to its role in both cyanobacteria [64] and in eukaryotic chloroplasts [49] in repairing PSII via the degradation of D1 proteins damaged by oxidative stress. All photosynthesis protein categories except PSI (violet) and light harvesting complexes associated with PSI (pink) and PSII (fuchsia) were significantly different from the overall photosynthesis mean peak time of 10:53 a.m. (Watson-Wheeler Test of Homogeneity of Means, FDR <0.05).

The timing of most of our photosynthesis ORFs is consistent with previous findings for naturally occurring picoplankton assemblages (Fig. S17). Similar photosynthetic cascades have also been observed in algae grown in light: dark conditions. In Micromonas pusilla, photosynthesis components show pronounced transcriptional changes in connection with the transition away from dawn [65]. In a higher resolution study of Chlamydomonas [51], patterns similar to those observed here were observed, but shifted slightly later, with B6F peaking early in the subjective day ( ZT4; 10 a.m.), followed by LHCI, PSI, and PSII in the middle of the subjective day ( ZT7; 1 p.m.), and LHCII last (ZT8; 2 p.m.). Likewise, in the diatom, Phaeodactylum, light harvesting machinery also peaks in the late afternoon [6]. This relative delay could be an effect of comparing 12:12-h light:dark cycles with natural conditions where daylight persists longer than $12 \mathrm{~h}$.

Surprisingly, PSI reaction center ORFs, psaA and $p s a B$, consistently peaked at night ( 9:30 p.m.) in cyanobacteria and the chloroplasts of chlorophytes, haptophytes, and pelagophytes (Fig. 5; dark red), rather than forming part of the daytime expression cascade. This runs contrary to previous findings for Prochlorococcus, where $p s a A$ and $p s a B$ have been shown to peak around 8 a.m. in environmental [11] and noon in laboratory [66] settings. This difference could possibly be explained by the iron-limited setting of our drift track. Iron-rich components of PSI are downregulated during iron stress in Prochlorococcus [67], and $p s a A$ expression is specifically controlled by an Feresponsive regulator in Chlamydomonas [68]. Deviations from the midday photosynthetic cascade also occurred in PSI and B6F, the two electron transport chain components that bind the most iron-sulfur clusters and are iron-stress responsive in diatoms [69]. However, to the best of our knowledge, such a dramatic shift in expression has not been previously been observed for $p s a A / p s a B$ and its cause is ultimately unknown.

\section{Diel transcriptional patterns vary across taxa}

The percent of the overall transcriptome with significant 24-h oscillations varied greatly between taxonomic groups, and was highest in Ostreococcus (nearly 25\%) and lowest in dinoflagellates $(<1 \%$; Fig. 3a). This difference could be explained by varied biological mechanisms for responding to sunlight. For example, dinoflagellates $[70,71]$ and ciliates [72] likely rely on post-transcriptional or post-translational mechanisms to a great degree. Here, dinoflagellates exhibited relatively consistent expression profiles that were anomalously highly correlated for eukaryotes ( $r=0.57$; Fig. S11a).

Dinoflagellates have been suggested to regulate their transcription differently than other algae and primarily respond to the environment post-transcriptionally [71, 73-77]. Dinoflagellate circadian oscillations have usually been observed at the level of translation [78, 79], with reports of only 3\% of Pyrocystis lunula genes being transcribed on a day/night cycle [70] and even circadiancontrolled cell-cycle regulators being post-transcriptionally controlled in Karenia brevis [71]. In Lingulodinium polyedrum, iron superoxide dismutase protein levels peak at midday, despite arrhythmic mRNA [73].

Despite their post-transcriptional response strategy, we detected 13 significantly periodic dinoflagellate nuclear ORFs, all of which recruited at least 69 reads. Eleven peaked in the early day and consisted of photosynthesisrelated ORFs (chlorophyll A-B binding proteins or GAPDH), hypothetical proteins, and ATP sulfurylase, which catalyzes the first step in sulfate assimilation [80]. The remaining two ORFs both peaked around 1 a.m. and consisted of karyopherin alpha, an adaptor protein responsible for importing proteins to the nucleus, and a small ubiquitin-related modifier protein involved in posttranslational modification. Diel cycling of such protein modifiers could shed light on currently cryptic diel behavior, such as bioluminescence, in dinoflagellates.

In contrast to the dinoflagellate and ciliate results, the high percentage of periodic ORFs in other taxa could be explained by light-synchronized division (as in 
A

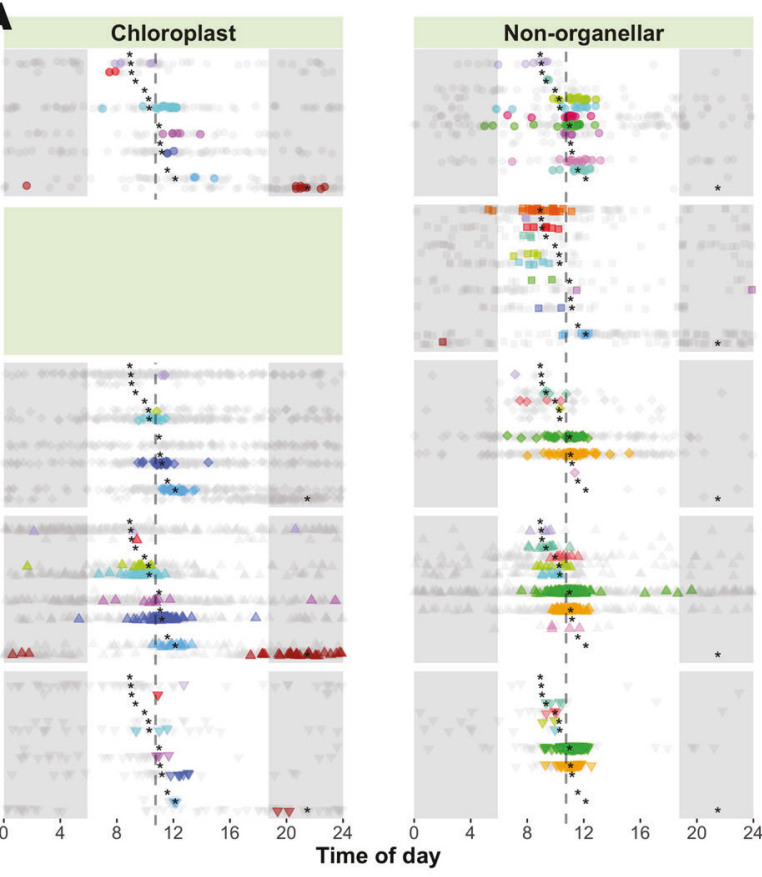

B

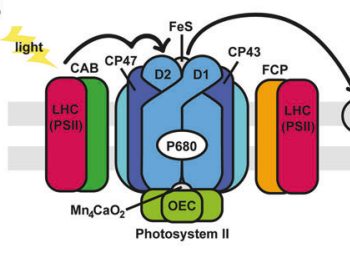

C
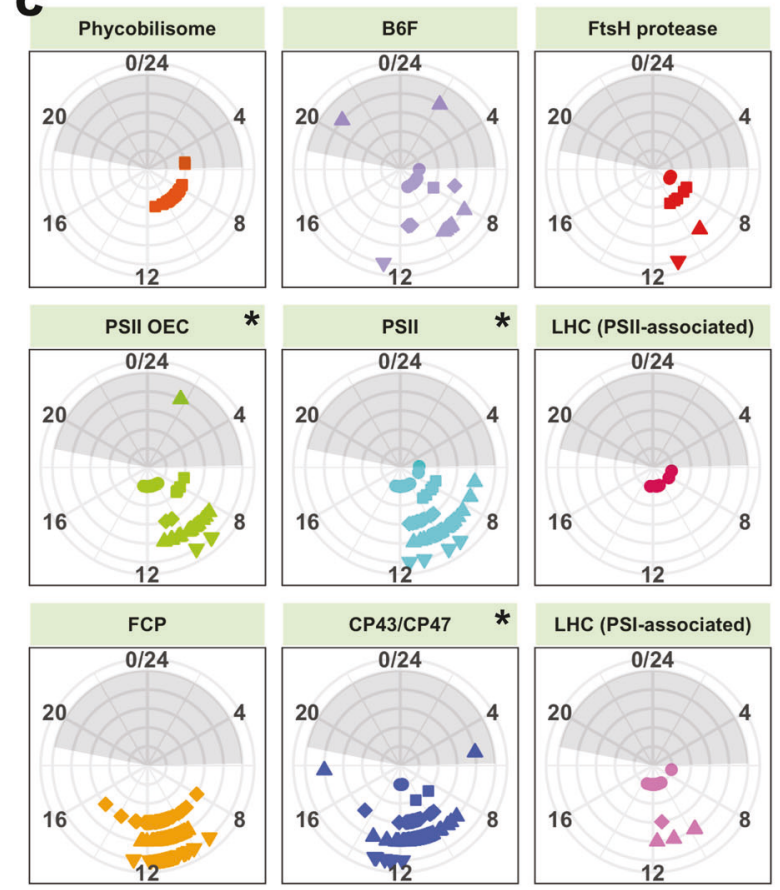

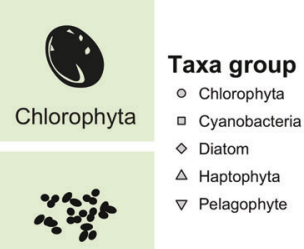

Cyanobacteria Functional annotation

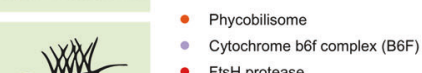

Cytochrome b6f complex (B6F)

- Ferredoxin-NADP+ reductase (FNR)

- Flavodoxin (FD)

PSII oxygen evolving complex (OEC)

- Photosystem II (PSII)

- LHC (PSIl-associated)

Chlorophyll A-B binding protein (CAB)

- Photosystem I (PSI)

Fucoxanthin chlorophyll protein (FCP)

PSII antenna (CP43/CP47)

- LHC (PSI-associated)

Prasinophyte LHC

PSII reaction center (D1/D2)

- PSI reaction center (psaA/psaB)
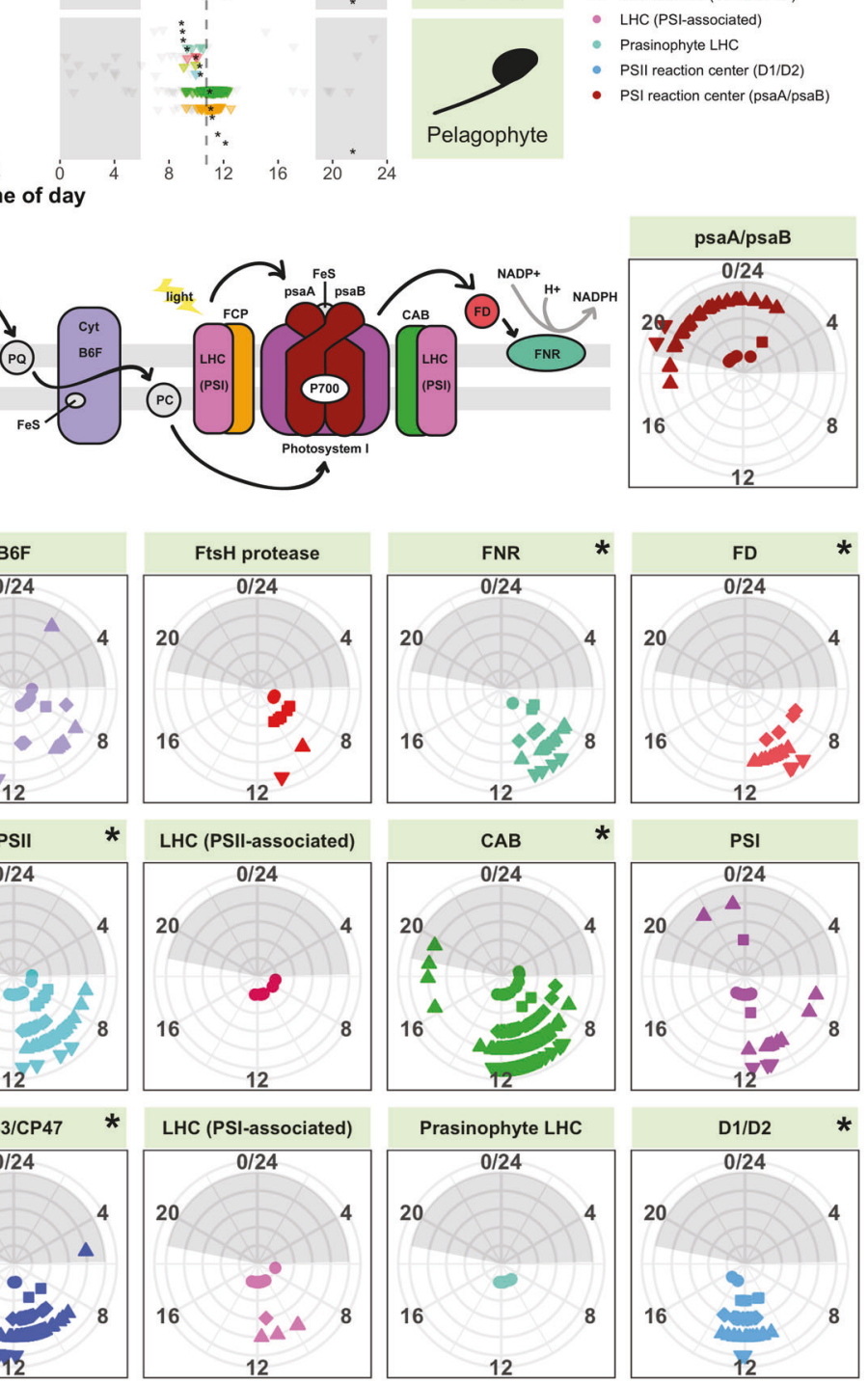
Fig. 5 Peak expression time of large fraction ab initio ORFs involved in photosynthesis. Night is indicated by gray shading. a Cascade of peak expression time occurs across diverse phytoplankton lineages. ORFs are plotted by chloroplast encoded (left) and non-organellar (right). Significantly periodic ORFs (HRA; FDR $\leq 0.1$ ) are colored by functional annotation (legend, right) and plotted in the same order as shown in the legend; insignificant ORFs are shown in grey. Asterisks denote functional annotation means across taxa groups that differ significantly (Watson-Wheeler Test of homogeneity of means, averaged over 1000 iterations to break ties, and Benjamini-Hochberg FDR <0.05) from the overall mean peak expression time (dashed gray line; 10:53 a.m.). b Illustration of the photosynthetic apparatus, colored by functional annotations from parts $(\mathbf{a}, \mathbf{c})$. Components with fewer than ten significantly periodic ORFs (pastoquinone (PQ), plastocyanin (PC)) are depicted in gray. Black arrows denote electron transport. c Conservation of peak expression time across phytoplankton lineages. Taxa groups are distinguished by shape (legend, top right) and radius (innermost: chlorophyta, outermost: pelagophyte). A Watson-Williams Test of homogeneity of means was performed on each functional group to determine taxonomic differences in peak expression time. Annotations with significantly different peak expression time across taxa groups (Benjamini-Hochberg FDR <0.05) are indicated with an asterisk

Ostreococcus), and cyclic expression of transcriptional machinery such as the preinitiation complex, RNA polymerase, and transcription factors in prasinophytes, Synechococcus, haptophytes, and pelagophytes (Fig. S16c).

In our data and the literature, diel partitioning of large portions of the transcriptome is a strategy most often adopted by phytoplankton with small cells and fast division rates. Diel transcription could allow such "streamlined" organisms to synchronize their protein pool with their transcript pool without manufacturing a large number of ribosomes. Temporally segregating a given transcript would increase its proportional abundance at the time of translation, which, according to information theory [81], could decrease fluctuations in protein number caused by ribosome sampling stochasticity. This could also provide an evolutionary motivation for producing precise waves of transcription for proteins that do not oscillate on a day/night cycle, as has been the perplexing case for the majority of genes in S. elongatus $[54,55]$ and $O$. tauri $[56]$. In contrast, we may observe fewer cyclic transcripts in larger organisms (e.g., ciliates, dinoflagellates) because they have the resources to maintain large transcript pools across all times of day. Indeed, large transcript pools could also provide greater flexibility in response to sudden environmental change, which may benefit the heterotrophic capabilities of these large taxa.

\section{Host-virus interactions}

We observed a diversity of viruses infecting bacteria and eukaryotes in both size classes (Fig. 6, S18). Viruses infecting large phytoplankton (e.g., Heterocapsa, Chaetoceros, Emiliania, and Phaeocystis) were enriched in the large fraction (Supplementary Dataset 10), whereas, in the small fraction, bacteriophages corresponding to several of the abundant bacterial groups were enriched (e.g. Pelagibacter phage, $\log _{2} \mathrm{FC}=11 ;$ Roseobacter phage, $\log _{2} \mathrm{FC}=$ 7.4; Vibrio phage, $\log _{2} \mathrm{FC}=5.2$; Supplementary Dataset 10; Supplementary File 1).

In the large size class, the majority of viruses were dsDNA viruses (74\%), but we also observed RNA viruses that infect phytoplankton [82] and labyrinthulids. While RNA virus reads could represent either transcribed mRNA or RNA genomic material, DNA virus transcripts indicate an active infection.

Remarkably, rather than host and virus expression being anticorrelated, as one might expect from kill-the-winner theory [83], co-expression was observed between dsDNA viruses and their hosts, which were homologous to diverse reference taxa including heterotrophic bacteria (e.g., Pelagibacter, Enterobacteria), cyanobacteria (e.g., Synechococcus, Prochlorococcus), photosynthetic eukaryotes (e.g., Bathycoccus, Micromonas, Ostreococus lucimarinus), and predatory heterotrophic eukaryotes (e.g., Cafeteria roenbergensis; Fig. 6, S18; pink boxes). One exception was Phaeocystis, with its aggregate gene expression peaking during daylight hours while both the giant Phaeocystis globosa virus and its virophage peaked synchronously at night. In addition, a virus infecting Ostreococcus Clade OII (OtV2) had clear night peaks in transcription, a phenomenon that has only ever been observed in the laboratory in experiments with the most distant of other Ostreococcus species, O. tauri, when infected by OtV5 [84]. Cyanophages also had peak expression at night, as previously observed [12]. The coordinated expression we observe between dsDNA viruses and hosts may result from replication of large viruses being more demanding on host metabolism [85, 86]. However, because we sequence bulk populations, we cannot be certain that host and virus transcripts originate from the same cell.

Unlike the predominance of host:dsDNA virus coexpression, ssRNA viruses related to those infecting the diatom, Chaetoceros, and the labyrinthulid, Aurantiochytrium were not co-expressed with their putative hosts. Rather, virus RNA molecule abundance lagged behind host transcription (Fig. 6; yellow boxes).

Most of the reference viruses that were used for gene mapping in our analyses have been well characterized. In laboratory experiments, it has been shown that their lytic cycles are $24-48 \mathrm{~h}$ in length even under various forms of nutrient limitation [82, 84, 87-89]. Hence, the detection of daily, closely synchronized transcription over more than two day/night periods suggests that a subset of each population of the major microbial players in this system, whether photosynthetic or not, was infected and lysed multiple times during the time course. Thus, rather than a few taxa being in a bloom scenario with epidemiology that 


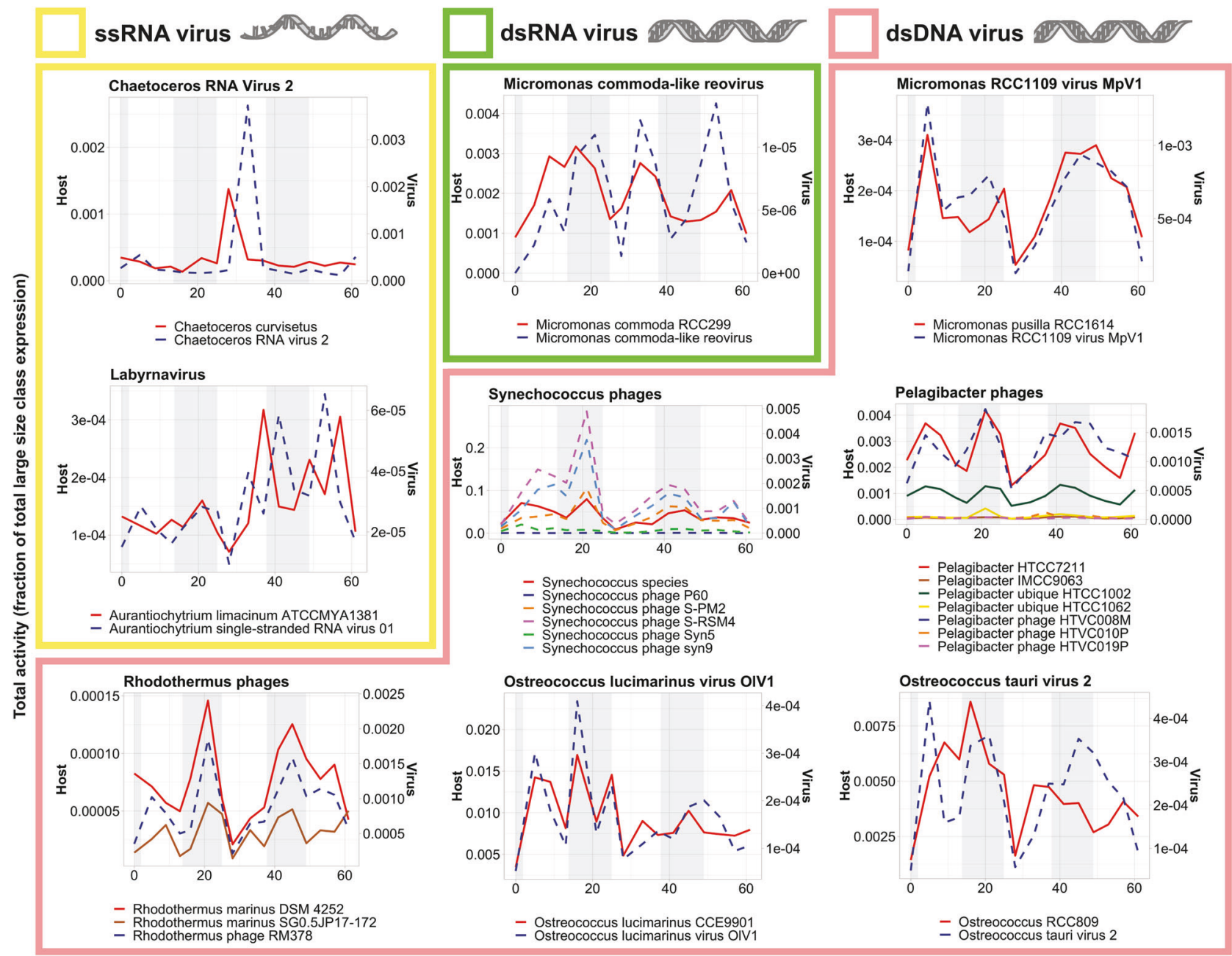

Time (hours)

Fig. 6 Virus/host dynamics in the large size class. Viruses and hosts are annotated as the closest reference available in our database, as determined by LPI. Library normalized expression of ORFs classified as ssRNA (yellow), dsRNA (green), and dsDNA (pink) viruses and their putative hosts by LPI are shown. Putative host expression is represented by solid lines and corresponds to left y-axes; virus expression is represented by dashed lines and corresponds to the right $y$-axes. Night hours are shaded in gray. Note that OtV2 infects RCC393, an Ostreococcus Clade OII species, not O. tauri. OtV2 was isolated against Ostreococcus Clade OII isolate RCC393 [94] which

would facilitate a massive viral lysis event, most taxa appeared to be under perpetual predation by viruses.

\section{Conclusions and future directions}

We present results from an often iron-limited, high-nutrient, low-chlorophyll setting in the eastern north Pacific [21]. We observed a pronounced transcriptional response indicative of existing iron limitation as well as a mechanism for seasonal adaptation to low iron and long photoperiod. We demonstrate that future measurements of diel transcription have the potential to elucidate not just daily, but also has $99 \% 18 \mathrm{~S}$ rDNA identity to the genome sequenced Clade OII isolate RCC809 used in our mapping analysis. Likewise, the M. commoda-like reovirus infects the strain LAC38, which was initially misreported as being $M$. pusilla and has been renamed here according to proper species assignment of the host [87]. Interestingly, while picoprasinophyte populations mapping most closely to Micromonas pusilla were coactive with a dsDNA virus, populations mapping most closely to Micromonas commoda (RCC299) were coactive with a dsRNA virus [87, 95]

seasonal, phytoplankton physiology by considering the implications of varied day/night translation rates. Due to its high resolution and semi-Lagrangian nature, samples collected from this drift track present an opportunity to study in situ phytoplankton physiological responses to day/night cycling-something rarely investigated for eukaryotes. We report, for the first time in nature, diel cycling transcription across major phytoplankton lineages. The proportion of genes cycling varied taxonomically, possibly reflecting differences in life strategy or post-transcriptional regulation.

Notably, laboratory observations of marine phytoplankton (e.g., Thalassiosira [90], Ostreococcus [47], Synechococcus 
[91], and Prochlorococcus [66]) report larger percentages of the transcriptome oscillating than we observed. This is likely due to increased statistical power enabled by deeper sequencing and higher percentages of mapped reads (i.e., mapping to a single model genome) as well as greater replication [92], but may also reflect physiological differences between ideal growth conditions and the patchy, dynamic nature of the marine environment.

Regardless of the proportion of genes cycling, functional partitioning of cycling genes was common across phytoplankton, pointing to a shared need to prepare for the daily onset of solar radiation and partition metabolic activity accordingly. Whereas heterotrophic bacterioplankton have been observed to display consecutive peaks in translation and oxidative phosphorylation-related transcription throughout the day [13], phytoplankton showed largely synchronized transcriptional timing. This may reflect differences between heterotrophic and photosynthetic life strategies. The unique metabolic needs of one bacterioplankton species might allow it to benefit from temporal association with another, but the largest driver of phytoplankton energetics is solar energy, which is concurrently available to all taxa. Our observation of a taxonomically conserved cascade of photosynthetic activity centered around $\sim 11$ a.m. and relegation of cell division to night $[44,45]$ may be explained by peak solar radiation and the risk of oxidative stress: both selective pressures that are shared by all photosynthetic organisms.

In addition to abiotic stressors, diverse phytoplankton and bacterial taxa appeared to be coping with viral infections, evidenced by high levels of viral RNA that often tracked putative host expression patterns. Indeed, the short lytic cycle of some of the closest viral references indicates that many host populations likely experienced multiple consecutive cycles of growth and viral lysis within the $\sim 2.6$ -day drift.

To date, in situ molecular sampling of large phytoplankton in the environment has not been applied widely, but future drifts have the potential to tease apart drivers of productivity in varied ocean conditions. Our results highlight the diversity of uncultured oceanic phytoplankton who remain "microbial dark matter" and the complexities of biogeochemical cycling by community interactions that are yet to be elucidated. We demonstrate that this technology allows for the observation of phytoplankton communities within the context of their natural biotic interactions and dynamic abiotic stressors. Such contextualization is an important step towards ascertaining global phytoplankton resilience to perturbation, and in turn, the resilience of the ecosystem services they provide.

Acknowledgements Cruise work was supported by the David and Lucile Packard Foundation through an annual grant to MBARI (FPC,
CAS, and AZW). This study was supported by the National Science Foundation (NSF-OCE-1756884, NSF-OCE-1637632), United States Department of Energy Genomics Science program (DE-SC0008593 and DE-SC0018344), NOAA (NA15OAR4320071), and the Gordon and Betty Moore Foundation grant GBMF3828 (AEA). BK was funded by NSF graduate research fellowship DGE1144086. We would like to thank J. Ryan for AUV data depiction shown in Figure S1A and J. Giammona, A. Millar, and S. Smith for helpful discussions.

\section{Compliance with ethical standards}

Conflict of interest The authors declare that they have no conflict of interest.

Publisher's note: Springer Nature remains neutral with regard to jurisdictional claims in published maps and institutional affiliations.

Open Access This article is licensed under a Creative Commons Attribution 4.0 International License, which permits use, sharing, adaptation, distribution and reproduction in any medium or format, as long as you give appropriate credit to the original author(s) and the source, provide a link to the Creative Commons license, and indicate if changes were made. The images or other third party material in this article are included in the article's Creative Commons license, unless indicated otherwise in a credit line to the material. If material is not included in the article's Creative Commons license and your intended use is not permitted by statutory regulation or exceeds the permitted use, you will need to obtain permission directly from the copyright holder. To view a copy of this license, visit http://creativecommons. org/licenses/by/4.0/.

\section{References}

1. Behrenfeld MJ, O'Malley RT, Siegel DA, McClain CR, Sarmiento JL, Feldman GC, et al. Climate-driven trends in contemporary ocean productivity. Nature 2006;444:752-5.

2. Buchan A, LeCleir GR, Gulvik CA, Gonzalez JM. Master recyclers: features and functions of bacteria associated with phytoplankton blooms. Nat Rev Microbiol. 2014;12:686-98.

3. Suttle CA. Viruses in the sea. Nature 2005;437:356-61.

4. Sarthou G, Timmermans KR, Blain S, Tréguer P. Growth physiology and fate of diatoms in the ocean: a review. J Sea Res. 2005;53:25-42.

5. Falkowski PG, Raven JA. Aquatic photosynthesis. 2nd ed. 41 William Street, Princeton, New Jersey: Princeton University Press; 2013. p. 488.

6. Smith SR, Gillard JTF, Kustka AB, McCrow JP, Badger JH, Zheng H, et al. Transcriptional orchestration of the global cellular response of a model pennate diatom to diel light cycling under iron limitation. PLoS Genet. 2016;12:e1006490.

7. Guo J, Wilken S, Jimenez V, Choi CJ, Ansong C, Dannebaum R, et al. Specialized proteomic responses and an ancient photoprotection mechanism sustain marine green algal growth during phosphate limitation. Nat Microbiol 2018;3:781-90.

8. Allen AE, LaRoche J, Maheswari U, Lommer M, Schauer N, Lopez PJ, et al. Whole-cell response of the pennate diatom Phaeodactylum tricornutum to iron starvation. Proc Natl Acad Sci USA. 2008;105:10438-43.

9. Scholin CA, Birch J, Jensen SRM III, Massion E, Pargett D, et al. The quest to develop ecogenomic sensors: a 25-year history of the Environmental Sample Processor (ESP) as a case study. Oceanography. 2017;30:100-13.

10. Ottesen EA, Young CR, Eppley JM, Ryan JP, Chavez FP, Scholin $\mathrm{CA}$, et al. Pattern and synchrony of gene expression among 
sympatric marine microbial populations. Proc Natl Acad Sci USA. 2013;110:E488-97.

11. Ottesen EA, Young CR, Gifford SM, Eppley JM, Marin R, Schuster SC, et al. Multispecies diel transcriptional oscillations in open ocean heterotrophic bacterial assemblages. Science. 2014;345:207-12.

12. Aylward FO, Boeuf D, Mende DR, Wood-Charlson EM, Vislova A, Eppley JM, et al. Diel cycling and long-term persistence of viruses in the ocean's euphotic zone. Proc Natl Acad Sci USA. 2017;201714821. http://www.pnas.org/lookup/doi/10.1073/pnas. 1714821114

13. Aylward FO, Eppley JM, Smith JM, Chavez FP, Scholin CA, DeLong EF. Microbial community transcriptional networks are conserved in three domains at ocean basin scales. Proc Natl Acad Sci USA. 2015;112:5443-8.

14. Bertrand EM, McCrow JP, Moustafa A, Zheng H, McQuaid JB, Delmont TO, et al. Phytoplankton-bacterial interactions mediate micronutrient colimitation at the coastal Antarctic sea ice edge. Proc Natl Acad Sci USA. 2015;112:9938-43.

15. Altschul SF, Gish W, Miller W, Myers EW. \& Lipman DJ. Basic local alignment search tool. J. Mol. Biol. 1990;215:403-10.

16. Podell S, Gaasterland T. DarkHorse: a method for genome-wide prediction of horizontal gene transfer. Genome Biol 2007;8:R16.

17. Bender SJ, Moran DM, McIlvin MR, Zheng H, McCrow JP, Badger $\mathrm{J}$, et al. Colony formation in Phaeocystis antarctica: connecting molecular mechanisms with iron biogeochemistry. Biogeosciences 2018;15:4923-42.

18. Langfelder P, Horvath S. WGCNA: an R package for weighted correlation network analysis. BMC Bioinform. 2008;9:559.

19. Bruland KW, Rue EL, Smith GJ. Iron and macronutrients in California coastal upwelling regimes: implications for diatom blooms. Limnol Oceanogr 2001;46:1661-74.

20. Hutchins DA, Bruland KW. Iron-limited diatom growth and Si: $\mathrm{N}$ uptake ratios in a coastal upwelling regime. Nature 1998;393:561-4.

21. Biller DV, Bruland KW. The central California Current transition zone: a broad region exhibiting evidence for iron limitation. Prog Oceanogr 2014;120:370-82.

22. Till CP, Solomon JR, Cohen NR, Lampe RH, Marchetti A, Coale $\mathrm{TH}$, et al. The iron limitation mosaic in the California Current System: factors governing Fe availability in the shelf/near-shelf region. Limnol Oceanogr. 2018;64:1-15.

23. Brzezinski MA, Krause JW, Bundy RM, Barbeau KA, Franks P, Goericke R, et al. Enhanced silica ballasting from iron stress sustains carbon export in a frontal zone within the California Current. J Geophys Res Ocean. 2015;120:4654-69.

24. Potvin M, Lovejoy C. PCR-based diversity estimates of artificial and environmental $18 \mathrm{~S}$ rRNA gene libraries. J Eukaryot Microbiol. 2009;56:174-81.

25. Sudek S, Everroad RC, Gehman ALM, Smith JM, Poirier CL, Chavez FP, et al. Cyanobacterial distributions along a physicochemical gradient in the Northeastern Pacific Ocean. Environ Microbiol 2015;17:3692-707.

26. Demir-Hilton E, Sudek S, Cuvelier ML, Gentemann CL, Zehr JP, Worden AZ. Global distribution patterns of distinct clades of the photosynthetic picoeukaryote Ostreococcus. ISME J 2011;5:1095-107.

27. Limardo AJ, Sudek S, Choi CJ, Poirier C, Rii YM, Blum M, et al. Quantitative biogeography of picoprasinophytes establishes ecotype distributions and significant contributions to marine phytoplankton. Environ Microbiol 2017;19:3219-34.

28. Simmons MP, Sudek S, Monier A, Limardo AJ, Jimenez V, Perle $\mathrm{CR}$, et al. Abundance and biogeography of picoprasinophyte ecotypes and other phytoplankton in the eastern North Pacific Ocean. Appl Environ Microbiol. 2016;82:1693-705.
29. Griffith P, Douglas D, Wainright S. Metabolic activity of sizefractionated microbial plankton in estuarine, near-shore, and continental shelf waters of Georgia. Mar Ecol Prog Ser. 1990;59:263-70.

30. Allen LZ, Allen EE, Badger JH, McCrow JP, Paulsen IT, Elbourne LD, et al. Influence of nutrients and currents on the genomic composition of microbes across an upwelling mosaic. ISME J 2012;6:1403-14.

31. Ganesh S, Parris DJ, Delong EF, Stewart FJ. Metagenomic analysis of size-fractionated picoplankton in a marine oxygen minimum zone. ISME J 2013;8:187-211.

32. Bochdansky AB, Clouse MA, Herndl GJ. Eukaryotic microbes, principally fungi and labyrinthulomycetes, dominate biomass on bathypelagic marine snow. ISME J 2017;11:362-73.

33. Edwards JL, Smith DL, Connolly J, McDonald JE, Cox MJ, Joint I, et al. Identification of carbohydrate metabolism genes in the metagenome of a marine biofilm community shown to be dominated by Gammaproteobacteria and Bacteroidetes. Genes. 2010;1:371-84.

34. Christensen PJ. The history, biology, and taxonomy of the Cytophaga group. Can J Microbiol. 1977;23:1599-653.

35. Tani K, Nasu M. Roles of extracellular DNA in bacterial ecosystem. In: Kikuchi Y, Rykova EY, editors. Extracellular nucleic acids, nucleic acids and molecular biology. Berlin: Springer; 2010. p. 25-37.

36. Meibom KL, Blokesch M, Dolganov NA, Wu CY, Schoolnik GK. Chitin induces natural competence in Vibrio cholerae. Science. 2005;310:1824-7.

37. Janouškovec J, Gavelis GS, Burki F, Dinh D, Bachvaroff TR, Gornik SG, et al. Major transitions in dinoflagellate evolution unveiled by phylotranscriptomics. Proc Natl Acad Sci USA. 2017;114:E171-80.

38. Harmer SL, Hogenesch JB, Straume M, Chang HS, Han B, Zhu T, et al. Orchestrated transcription of key pathways in arabidopsis by the circadian clock. Science. 2000;290:2110-3.

39. Liu Y, Tsinoremas NF, Johnson CH, Lebedeva NV, Golden SS, Ishiura $\mathrm{M}$, et al. Circadian orchestration of gene expression in cyanobacteria. Genes Dev 1995;9:1469-78.

40. Corellou F, Schwartz C, Motta J-P, Djouani-Tahri EB, Sanchez F, Bouget F-Y. Clocks in the green lineage: comparative functional analysis of the circadian architecture of the picoeukaryote ostreococcus. Plant Cell. 2009;21:3436-49.

41. Djouani-Tahri EB, Christie JM, Sanchez-Ferandin S, Sanchez F, Bouget FY, Corellou F. A eukaryotic LOV-histidine kinase with circadian clock function in the picoalga Ostreococcus. Plant J. 2011;65:578-88.

42. Jaubert M, Bouly JP, Ribera d'Alcalà M, Falciatore A. Light sensing and responses in marine microalgae. Curr Opin Plant Biol. 2017;37:70-7.

43. Hu SK, Connell PE, Mesrop LY, Caron DA. A hard day's night: diel shifts in microbial eukaryotic activity in the North Pacific Subtropical Gyre. Front Mar Sci. 2018;5:351.

44. Nikaido SS, Johnson CH. Daily and circadian variation in survival from ultraviolet radiation in chlamydomonas reinhardtii. Photochem Photobiol 2000;71:758.

45. Pittendrigh CS. Temporal organization: reflections of a Darwinian clock-watcher. Annu Rev Physiol. 1993;55:17-54.

46. de los Reyes P, Romero-Campero FJ, Ruiz MT, Romero JM, Valverde F. Evolution of daily gene co-expression patterns from algae to plants. Front Plant Sci. 2017;8:1-22.

47. Monnier A, Liverani S, Bouvet R, Jesson B, Smith JQ, Mosser J, et al. Orchestrated transcription of biological processes in the marine picoeukaryote Ostreococcus exposed to light/dark cycles. BMC Genom. 2010;11:192.

48. Covington MF, Maloof JN, Straume M, Kay SA, Harmer SL. Global transcriptome analysis reveals circadian regulation of key 
pathways in plant growth and development. Genome Biol. 2008;9: R130.

49. Zaltsman A. Two types of FtsH protease subunits are required for chloroplast biogenesis and photosystem II repair in Arabidopsis. Plant Cell. 2005;17:2782-90.

50. Sweeney BM, Borgese MB. A circadian rhythm in cell division in a prokaryote, the cyanobacteria Synechococcus WH78031. J Phycol. 1989;25:183-6. p

51. Zones JM, Blaby IK, Merchant SS, Umen JG. High-resolution profiling of a synchronized diurnal transcriptome from Chlamydomonas reinhardtii reveals continuous cell and metabolic differentiation. Plant Cell 2015;27:2743-69.

52. Müller M, Antia A, LaRoche J. Influence of cell cycle phase on calcification in the coccolithophore Emiliania huxleyi. Limnol Oceanogr 2008;53:506-12.

53. Jacquet S, Partensky F, Lennon JF, Vaulot D. Diel patterns of growth and division in marine picoplankton in culture. J Phycol 2001;37:357-69.

54. Seaton DD, Graf A, Baerenfaller K, Stitt M, Millar AJ, Gruissem W. Photoperiodic control of the Arabidopsis proteome reveals a translational coincidence mechanism. Mol Syst Biol. 2018;14:e7962.

55. Guerreiro ACL, Benevento M, Lehmann R, van Breukelen B, Post $\mathrm{H}$, Giansanti P, et al. Daily rhythms in the cyanobacterium synechococcus elongatus probed by high-resolution mass spectrometry-based proteomics reveals a small defined set of cyclic proteins. Mol Cell Proteom. 2014;13:2042-55.

56. Noordally ZB, Hindle M, Martin SF, Seaton DD, Simpson TI, Le Bihan T, et al. Circadian protein regulation in the green lineage I. A phospho-dawn anticipates light onset before proteins peak in daytime. Running. BioRxiv. 2018.

57. Suzuki L, Johnson CH. Algae know the time of day: circadian and photoperiodic programs. J Phycol 2001;37:933-42.

58. Petroutsos D, Busch A, Janßen I, Trompelt K, Bergner SV, Weinl $\mathrm{S}$, et al. The chloroplast calcium sensor CAS is required for photoacclimation in Chlamydomonas reinhardtii. Plant Cell 2011;23:2950-63.

59. Falciatore A, D'Alcalà MR, Croot P, Bowler C. Perception of environmental signals by a marine diatom. Science. 2000;288:2363-6.

60. Bender SJ, Moran DM, McIlvin MR, Zheng H, McCrow JP, Badger $\mathrm{J}$, et al. Colony formation in Phaeocystis antarctica: Connecting molecular mechanisms with iron biogeochemistry. Biogeosciences. 2018;15:4923-42. https://www.biogeosciencesdiscuss.net/bg-2017-558/.

61. Scheibe R, Backhausen JE, Emmerlich V, Holtgrefe S. Strategies to maintain redox homeostasis during photosynthesis under changing conditions. J Exp Bot. 2005;56:1481-9.

62. McQuaid JB, Kustka AB, Oborník M, Horák A, McCrow JP, Karas BJ, et al. Carbonate-sensitive phytotransferrin controls high-affinity iron uptake in diatoms. Nature 2018;555:534-7.

63. Lampe RH, Mann EL, Cohen NR, Till CP, Thamatrakoln K, Brzezinski MA, et al. Different iron storage strategies among bloomforming diatoms. Proc Natl Acad Sci USA. 2018;115:E12275-84. http://www.pnas.org/lookup/doi/10.1073/pnas.1805243115.

64. Silva P, Thompson E, Bailey S, Kruse O, Mullineaux CW, Robinson $\mathrm{C}$, et al. FtsH is involved in the early stages of repair of photosystem II in Synechocystis sp PCC 6803. Plant Cell 2003;15:2152-64

65. Duanmu D, Bachy C, Sudek S, Wong C-H, Jimenez V, Rockwell NC, et al. Marine algae and land plants share conserved phytochrome signaling systems. Proc Natl Acad Sci USA. 2014;111:15827-32.

66. Zinser ER, Lindell D, Johnson ZI, Futschik ME, Steglich C, Coleman ML, et al. Choreography of the transcriptome, photophysiology, and cell cycle of a minimal photoautotroph, Prochlorococcus. PLoS One 2009;4:e5135.

67. Thompson AW, Huang K, Saito MA, Chisholm SW. Transcriptome response of high- and low-light-adapted Prochlorococcus strains to changing iron availability. ISME J 2011;5:1580-94.

68. Douchi D, Qu Y, Longoni P, Legendre-Lefebvre L, Johnson X, SchmitzLinneweber $\mathrm{C}$, et al. A nucleus-encoded chloroplast phosphoprotein governs expression of the photosystem I subunit PsaC in Chlamydomonas reinhardtii. Plant Cell 2016;28:1182-99.

69. Strzepek RF, Harrison PJ. Photosynthetic architecture differs in coastal and oceanic diatoms. Nature 2004;431:689-92.

70. Okamoto OK, Hastings JW. Novel dinoflagellate clock-related genes identified through microarray analysis. J Phycol 2003; 39:519-26.

71. Brunelle SA, Van Dolah FM. Post-transcriptional regulation of SPhase genes in the dinoflagellate, karenia brevis. J Eukaryot Microbiol. 2011;58:373-82.

72. Almeida R, Allshire RC. RNA silencing and genome regulation. Trends Cell Biol. 2005;15:251-8.

73. Okamoto OK, Robertson DL, Fagan TF, Hastings JW, Colepicolo P. Different regulatory mechanisms modulate the expression of a dinoflagellate ironsuperoxide dismutase. J Biol Chem. 2001;276:19989-93.

74. Alexander H, Rouco M, Haley ST, Wilson ST, Karl DM, Dyhrman ST. Functional group-specific traits drive phytoplankton dynamics in the oligotrophic ocean. Proc Natl Acad Sci USA. 2015;112:E5972-9.

75. Hackett JD, Anderson DM, Erdner DL, Bhattacharya D. Dinoflagellates: a remarkable evolutionary experiment. Am J Bot. 2004;91:1523-34.

76. Moustafa A, Evans AN, Kulis DM, Hackett JD, Erdner DL, Anderson DM, et al. Transcriptome profiling of a toxic dinoflagellate reveals a gene-rich protist and a potential impact on gene expression due to bacterial presence. PLoS One. 2010;5:e9688.

77. Carradec Q, Pelletier E, Da Silva C, Alberti A, Seeleuthner Y, Blanc-Mathieu R, et al. A global ocean atlas of eukaryotic genes. Nat Commun 2018;9:373.

78. Roenneberg T, Morse D. Two circadian oscillators in one cell. Nature 1993;362:362-4.

79. Brunelle SA, Hazard ES, Sotka EE, Van Dolah FM. Characterization of a dinoflagellate cryptochrome blue-light receptor with a possible role in circadian control of the cell cycle. J Phycol. 2007:43:509-18.

80. Prioretti L, Gontero B, Hell R, Giordano M. Diversity and regulation of ATP sulfurylase in photosynthetic organisms. Front Plant Sci. 2014;5:1-12.

81. MacKay DJC. Information theory, inference, and learning algorithms. vol. 41, Choice Reviews Online. Cambridge University Press; 2013. p. 41-5949-41-5949.

82. Nagasaki K. Dinoflagellates, diatoms, and their viruses. J Microbiol 2008;46:235-43.

83. Thingstad TF. Elements of a theory for the mechanisms controlling abundance, diversity, and biogeochemical role of lytic bacterial viruses in aquatic systems. Limnol Oceanogr 2000;45:1320-8.

84. Derelle E, Yau S, Moreau H, Grimsley NH. Prasinovirus attack of Ostreococcus is furtive by day but savage by night. J Virol 2017;92:01703-17. JVI

85. Sanchez EL, Lagunoff M. Viral activation of cellular metabolism. Virology 2015;479-480:609-18.

86. Thompson LR, Zeng Q, Kelly L, Huang KH, Singer AU, Stubbe $\mathrm{J}$, et al. Phage auxiliary metabolic genes and the redirection of cyanobacterial host carbon metabolism. Proc Natl Acad Sci USA. 2011;108:E757-64. 
87. Bachy C, Charlesworth CJ, Chan AM, Finke JF, Wong CH, Wei $\mathrm{CL}$, et al. Transcriptional responses of the marine green alga Micromonas pusilla and an infecting prasinovirus under different phosphate conditions. Environ Microbiol 2018;20:2898-912.

88. Proctor LM, Fuhrman JA. Viral mortality of marine bacteria and cyanobacteria. Nature 1990;343:60-2.

89. Puxty RJ, Evans DJ, Millard AD, Scanlan DJ. Energy limitation of cyanophage development: Implications for marine carbon cycling. ISME J. 2018;12:1273-86. https://doi.org/10.1038/ s41396-017-0043-3.

90. Ashworth J, Coesel S, Lee A, Armbrust EV, Orellana MV, Baliga NS. Genomewide diel growth state transitions in the diatom Thalassiosira pseudonana. Proc Natl Acad Sci USA. 2013;110:7518-23.
91. Cohen SE, Golden SS. Circadian rhythms in cyanobacteria. Microbiol Mol Biol Rev. 2015;79:373-85.

92. Hughes ME, Abruzzi KC, Allada R, Anafi R, Arpat AB, Asher G, et al. Guidelines for genome-scale analysis of biological rhythms. J Biol Rhythms. 2017;32:380-93.

93. Park MG, Kim M, Kim S. The acquisition of plastids/phototrophy in heterotrophic dinoflagellates. Acta Protozool 2014;53:39-50.

94. Weynberg KD, Allen MJ, Gilg IC, Scanlan DJ, Wilson WH. Genome sequence of Ostreococcus tauri virus OtV-2 throws light on the role of picoeukaryote niche separation in the ocean. J Virol 2011;85:4520-9.

95. Brussaard CPD, Noordeloos AAM, Sandaa RA, Heldal M, Bratbak G. Discovery of a dsRNA virus infecting the marine photosynthetic protist Micromonas pusilla. Virology 2004;319:280-91. 